\title{
Finite Element Analysis Electric Sightseeing Vehicle Frame Based on ANSYS
}

\author{
Jianwei Ma ${ }^{1, a,}$, Yuansheng Cui ${ }^{2, b}$, and Ziliang Feng ${ }^{1, c}$ \\ ${ }^{1}$ Department of Vehicle Engibeering, Xingtai Polytechnic, Xingtai, Hebei, China \\ ${ }^{2}$ Military Representative Office of PLA Air Force in Shandong Region, Jinan, Shandong, China \\ a94718894@qq.com, bfan_fan_0613@sina.com, c826840689@qq.com \\ *Corresponding author
}

Keywords: Frame, Electric Sightseeing Vehicle, Finite element, ANSYS

\begin{abstract}
Structural Parameters of frame of electric sightseeing vehicle are designed, three-dimensional model of frame is established using CATIA Software, static analysis of established frame model is conducted under full-load condition using ANSYS, the result shows that designed intensity satisfies intensity demand; modal analysis of frame is conducted using ANSYS Workbench, Some vibration modes of frame structure from seventh step to fifteenth step are obtained, the results show that the structure of the frame does not produce resonance phenomenon, and the reliability of the frame structure is verified. The analysis results provide reference for the design of electric sightseeing vehicle with good performance, and have high practical application and research value.
\end{abstract}

\section{Introduction}

At present, with the rapid development of the tourism industry, the electric sightseeing vehicle, as the product of the new green energy, will take the place of the original travel tools of the scenic spot and improve the safety and comfort of the tourist in the scenic area. The wide view of the sightseeing car can make the tourists have no more than the beautiful scenery of the scenic spot, and its anisotropy brings different experience to the tourist [1]. On the basis, the use of electric sightseeing vehicle conforms to the trend of the times, it has pollution-free emission and saves energy, it can alleviate the pressure of urban air pollution and energy scarcity stress [2]. It is an inevitable trend to replace the traditional fuel vehicles in scenic spots, campus, commercial streets and other areas. The generation of electric sightseeing vehicle conforms to the trend of green development in this century. It is a kind of transportation tool for sustainable development of society [3-4].

\section{Parameter Determination of Electric Sightseeing Vehicle Frame}

The outer size parameters of the electric sightseeing vehicle are the primary consideration of the frame structure design. Because the using environment of the electric sightseeing vehicle used in the scenic area is within the interior of tourist attractions, so the size of the designed electric sightseeing vehicle is not restricted under the premise of meeting the design requirements.

Referring to the existing three electric sightseeing vehicle in the market, the parameters of the designed electric sightseeing vehicle are shown in Table 1.

Table 1 Main parameters of electric sightseeing vehicle body

\begin{tabular}{lcccccccc}
\hline Parameters & $\begin{array}{c}\text { Body } \\
\text { length }\end{array}$ & $\begin{array}{c}\text { Frame } \\
\text { length }\end{array}$ & $\begin{array}{c}\text { Body } \\
\text { width }\end{array}$ & $\begin{array}{c}\text { Frame } \\
\text { width }\end{array}$ & $\begin{array}{c}\text { Body } \\
\text { height }\end{array}$ & $\begin{array}{c}\text { Ground } \\
\text { clearance }\end{array}$ & $\begin{array}{c}\text { Spread of } \\
\text { wheels }\end{array}$ & $\begin{array}{c}\text { Axle } \\
\text { base }\end{array}$ \\
\hline Value(mm) & 3900 & 3251 & 1200 & 1080 & 1900 & 150 & 1000 & 2400 \\
\hline
\end{tabular}




\section{Structure Design and Three-Dimensional Modeling of Frame}

The structure of the electric sightseeing vehicle frame adopts the fringe-beam frame, and the two main beams of the frame are arranged between the middle part of the longitudinal wheel of the frame, as the main weight bearing part of the frame, the middle part is added with a longitudinal beam to match the welding of the frame crossbeam, so the main part of the frame is formed to install support structure of the seat; the front and back parts of the frame structure adopts the upward curved beam, which provides convenient conditions for the layout and installation of the front and rear suspension of the sightseeing vehicle. In addition, the design provides convenience for the layout and installation of motor, battery, brake system and other parts; the design of the rear part of the electric sightseeing vehicle provides some space for the luggage. The three-dimensional model of the frame is constructed and assembled with CATIA software, it is shown in Figure.1.

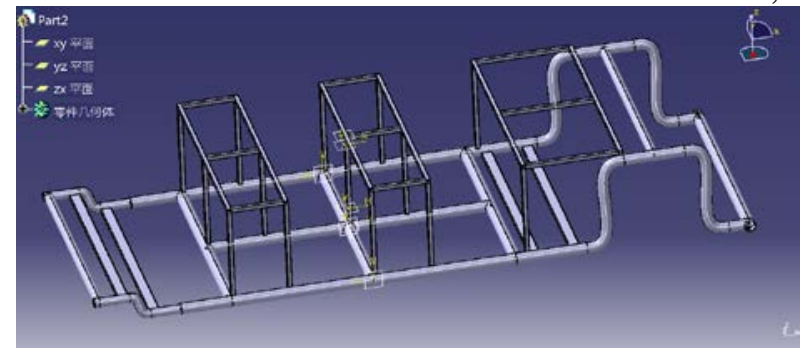

Fig .1 Three-dimensional model of frame

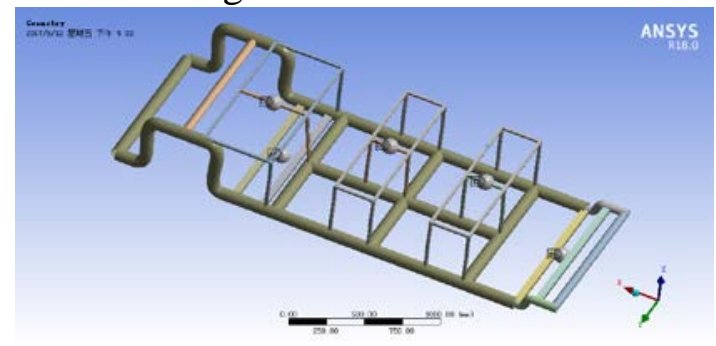

Fig. 2 Simplified model of frame

\section{Static Finite Element Analysis of Sightseeing Vehicle Frame}

The accuracy of the model plays a key role to results of finite elementary analysis. In order to make the static analysis of the frame more correct, the parameters set must be strict according to the actual operating condition of the frame. Before the statics analysis of the frame structure, it is necessary to define the properties of the material, define the reasonable boundary conditions, treat load, divide grid and so on, so as to get the finite element model of the frame. At the same time, it is necessary to simplify the three-dimensional model of the original frame structure in the three-dimensional design software before dividing the frame system into a grid, so that the better quality of the grid can be obtained [5].

\section{Definition of Material Properties of Frame Structure}

Q235 steel is used in this design. The data obtained by reference are obtained: the density is $7850 \mathrm{~kg} / \mathrm{cm} 3$, the modulus of elasticity is $206 \mathrm{Mpa}$, the Poisson's ratio is 0.3 , the yield limit is $235 \mathrm{Mpa}$, the thickness of the material is $1 \mathrm{~mm}$ [6].

\section{Determination of Load}

During the force analysis on the actual operating conditions, according to the load analysis of full load (a driver and seven passengers) the simplified model of the frame system is introduced into the ANSYS software (loading distribution point), as shown in Figure.2. The load of point A is the quality of the back row battery and the driving motor, it is $100 \mathrm{Kg}$, the load of point B is the quality of the front row console and the windshield and other parts, and it is $7 \mathrm{Kg}$, the point $\mathrm{C}$ is the quality of the rear passenger and the floor, and it is $143 \mathrm{Kg}$, point $\mathrm{D}$ is the quality of the middle row passengers and the floor, it is $143 \mathrm{~kg}$, point $\mathrm{E}$ is the quality of the front row passengers and the floor and other accessories, and it is $175 \mathrm{Kg}$. 


\section{Grid Partition}

The Grid partition schematic diagram of the frame structure of the sightseeing vehicle is shown in Figure.3. The final grid object has 2552 nodes and the number of units is 1291 .

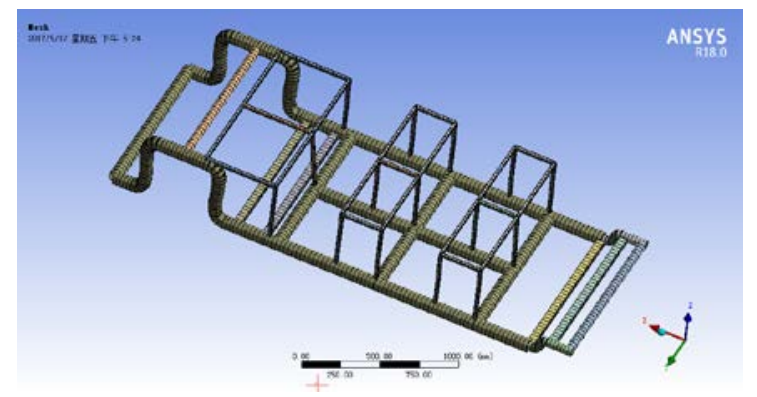

Fig. 3 Finite element model after dividing grid

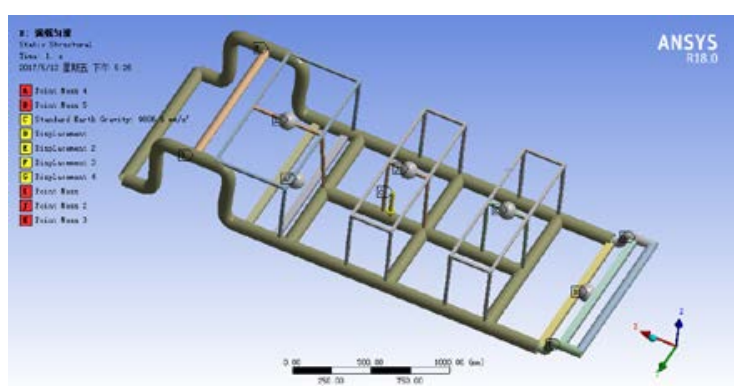

Fig. 4 Load distribution of frame under full load and uniform speed condition

\section{Constraint and Load Treatment under Full Load Bending Condition}

The maximum dynamic load coefficient is 2.5 when the frame is full load and bending. In order to ensure safety, the maximum dynamic load coefficient is 2.5 during simulating. The load distribution of frame structure under full load and uniform speed condition is shown in Figure.4. The model is imported into ANSYS to analyze and get the following results. The stress cloud of the frame is shown in Figure.5 and strain cloud is shown in Figure.6.

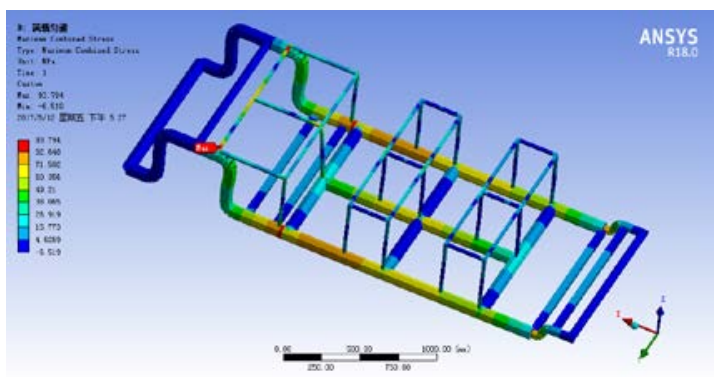

Fig. 5 The stress cloud of the frame under full load and uniform speed condition

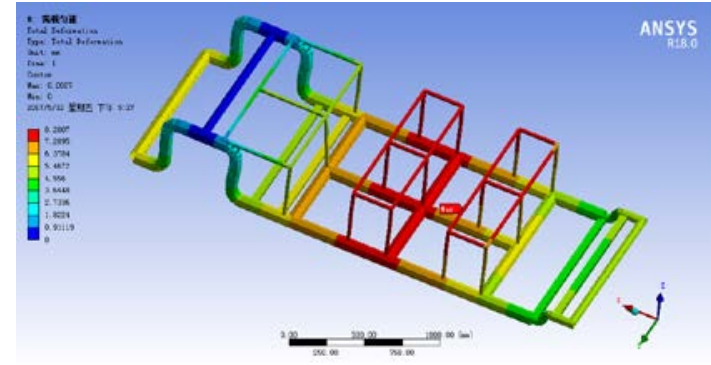

Fig. 6 Strain cloud of frame under full load and uniform speed condition

\section{Analysis Results of Full Load Bending Condition}

According to Figures.5 and 6, the overall stress distribution of the frame structure is relatively uniform, and the stress value is small, all are about 40Mpa. The dynamic load coefficient of vehicle on any road will not exceed 2.5. In the process of checking the structure strength of the frame, the maximum safety factor is 2.5, and the strength of the frame under full load and uniform speed condition is checked according to the Eq.1.

$$
\sigma \times n=93.8 \times 2.5=234.5 \mathrm{Mpa}<[\sigma]=235 \mathrm{Mpa}
$$

From calculation results, the maximum stress value of the frame structure is $234.5 \mathrm{Mpa}$, which is smaller than 235Mpa, under the yield limit of Q235, and the stress values are around 40Mpa in most parts of the frame structure, under the yield limit value of Q235. The deformation of the frame is small and the deformation is within a reasonable range. Through static finite element analysis of the frame under full load and uniform speed condition, it is known that the design of the frame fully meets the strength requirement and the design is reasonable. 


\section{Modal Analysis of a Sightseeing Vehicle Frame}

In the real-time running condition of the electric sightseeing vehicle, as the pavement of the scenic spot is mostly paved with asphalt, the effect of the vibration pattern of each step of frame to the vibration of the frame structure is different [7]. The contribution value of the first few steps is larger when driving, and the contribution value of the rear modal will be smaller and smaller. So the first vibration modes of 15 are analyzed.

First, the simplified model of the frame structure is introduced into the ANSYS Workbench software, and then the grid set of the finite element model is arranged and the first 15 step natural frequencies of the mode are calculated. The modal analysis of the frame is carried out using ANSYS software, and some vibration modes of the frame structure from seventh to fifteenth step are obtained, they are shown in Figure 7-12.

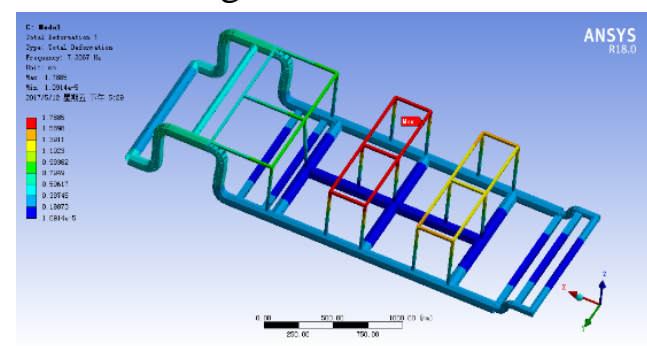

Fig.7 Seventh step

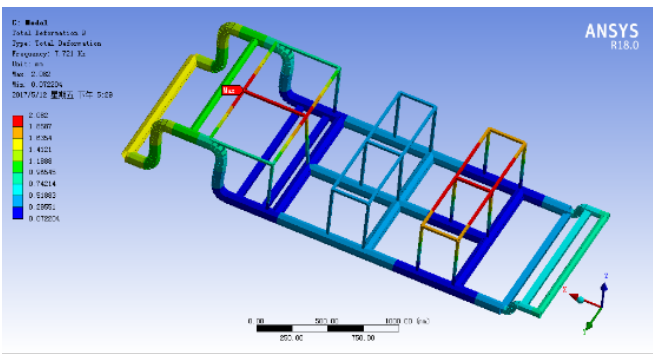

Fig.9 Ninth step

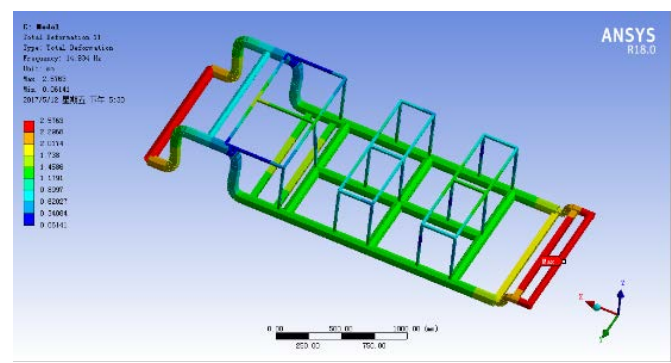

Fig.11 Eleventh step

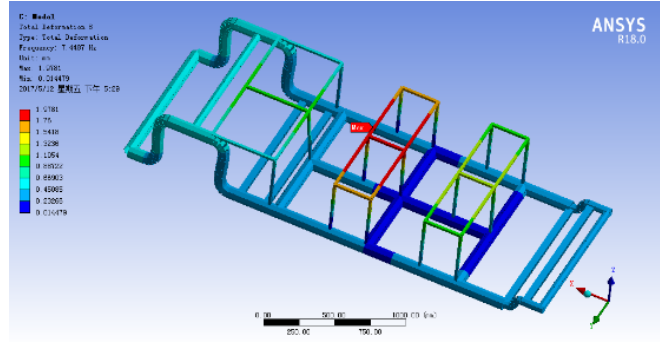

Fig.8 Eighth step

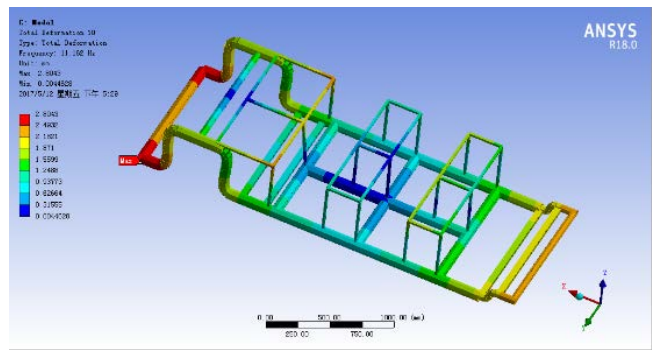

Fig. 10 Tenth step

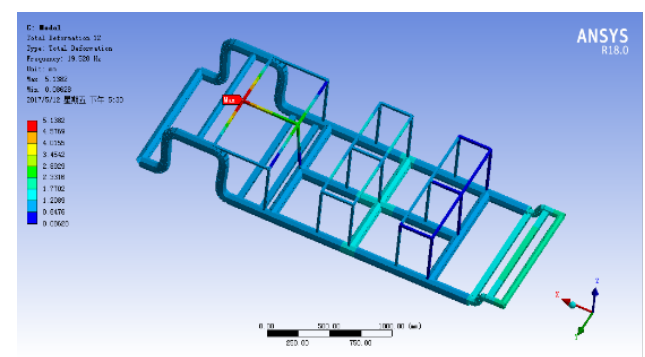

Fig. 12 Twelfth step

Calculation Results of Free Modal Analysis. The excitation source of vehicle vibration is mainly the displacement excitation caused by uneven road surface, and the additional excitation caused by the imbalance of the transmission parts of the driving system [8].

In the main exciting source of the electric sightseeing vehicle, the simple harmonic vibration excitation caused by the rotation of the electric motor is very small, so it is not considered. Therefore, the vehicle condition is the main consideration. The driving condition of the vehicle determines the excitation caused by the road. It can be obtained by Eq. 2 .

$$
\mathrm{f}=v / \lambda
$$

Where, the $f$ is the frequency of excitation, the $v$ the speed of the electric sightseeing vehicle; $\lambda$ is the pavement wavelength.

The road surface of the scenic area is paved with better asphalt pavement or lime, for the good driving road, $\lambda$ is $8 \mathrm{~m}$ usually, then the maximum value of $v$ is taken $25 \mathrm{~km} / \mathrm{h}(16.67 \mathrm{~m} / \mathrm{s})$, and the 
calculated $\mathrm{F}$ is $2.08 \mathrm{~Hz}$. The vibration pattern of the frame is analyzed. The first six natural frequencies of the frame are less than $1 \mathrm{~Hz}$. After the seven step, the inherent frequency of the frame is above $7 \mathrm{~Hz}$, so that the frame structure will not resonate with the external excitation of the frame. The natural frequency of the seventh step of the frame is $7.3867 \mathrm{~Hz}$. It is assumed that the external excitation of the frame makes it resonate, and $v$ is calculated to be $59.1 \mathrm{~m} / \mathrm{s}(212.7 \mathrm{~km} / \mathrm{h})$ according to the formula, which is more than the original designed speed of the frame. The excitation frequency that causes wheel imbalance is below $11 \mathrm{~Hz}$, and the frequency of the frame structure after the ten step is bigger than $11 \mathrm{~Hz}$, frequency of the first 9 steps are less than $11 \mathrm{~Hz}$, but the imbalance of the wheel can be completely controlled by improving the manufacturing process, so the probability of the resonance phenomenon of the frame will be greatly reduced. It can be seen that the structure design of sightseeing vehicle frame is reasonable.

\section{Conclusion}

The new type of electric sightseeing vehicle frame is designed based on an electric sightseeing vehicle. The new frame structure makes the passenger's space larger. The three-dimensional modeling of the frame is carried out with CATIA, and the overall thickening and strengthening design was carried out to make the whole vehicle have higher ride comfort and higher strength, and the finite element grid model of the frame was established by using ANSYS software, and the load situation of the frame structure was added and degree of freedom is constrained to make it close to the real driving condition of the whole vehicle, and strain and stress cloud map of the frame under bending condition is obtained via analysis and calculation. It is proved that the design of the new type frame is reasonable, through the natural frequencies and vibration modes of each step are analyzed. It is determined that the frame structure will not produce resonance, the reliability of the frame structure is verified.

\section{References}

[1] W.L. Gao. Chassis design and CAE analysis of hybrid sightseeing vehicle, G. Hunan University, (2013).

[2] P. F Zhang. Design and dynamics study of the electric vehicle frame in the field, G. Tianjin vocational and Technical Normal University, (2015).

[3] Kazuo, Niiyama. Analysis of Torsional Stiffness Share Rate of Truck Frame. SAE: Technical Paper Series, 18-21(1991).

[4] C.J Li. Finite element analysis and Simulation of key components of electric sightseeing vehicle, G. Qingdao Technological University (2015).

[5] P.G Du: The basic principle of finite element mesh generation. P.15-21, NO.01 (2000).

[6] Joseph C, Benedy K.. Light Metals in Automotive Applications. Light Met. Age, 34-35, 58 (2000).

[7] H.Y Long. Modal analysis and optimization design of electric vehicle frame, G. Hebei United University, (2015).

[8] M. Krawczuk. Moda. Analysis of the Low-pressure Frame of Steam Turbine. American Society of Mechanical Engineers, 275-287, 3(1995). 